\title{
Cognitive and Behavioral Effects of Multilayer-Release Methylphenidate in the Treatment of Children with Attention-Deficit/Hyperactivity Disorder
}

\author{
Russell Schachar, M.D., ${ }^{1}$ Abel Ickowicz, M.D.,1 Jennifer Crosbie, Ph.D., ${ }^{1,2}$, \\ Graeme A.E. Donnelly, M.Sc., ${ }^{4}$ Joseph L. Reiz, B.Sc., ${ }^{4}$ Paula C. Miceli, M.Sc., ${ }^{3,4}$ \\ Zoltan Harsanyi, B.Sc., M.L.S., M.B.A. ${ }^{4}$ and Andrew C. Darke, Ph.D. ${ }^{4}$
}

\begin{abstract}
Objective: The aim of this study was to compare the pharmacodynamics of a new multilayerrelease (MLR) formulation methylphenidate (MPH; Biphentin ${ }^{\circledR}$ ) with immediate-release (IR) MPH (Ritalin ${ }^{\circledR}$ ) in a double-blind, cross-over, placebo-controlled study in patients with attention-deficit/hyperactivity disorder (ADHD).

Method: Patients were randomized to equivalent doses of MPH as MLR (once per day), IR (twice per day) or placebo. Each treatment was taken for 1 week prior to repeated behavioral and cognitive laboratory evaluations on a single day in each phase of the crossover.

Results: Two girls and 15 boys $6.8-15.3$ years old (mean age $11.3 \pm 2.2$ years) participated. Both MLR and IR MPH significantly reduced the Stop Signal Reaction Time $(p=0.0001, p=$ 0.0005), the Errors of Omission on the Continuous Performance Task $(p=0.0039, p=0.0001)$, the IOWA-Conners Inattention/Overactivity Index $(p=0.0001, p=0.0001)$, and increased the Clinical Global Impressions (CGI) Efficacy Index $(p=0.0001, p=0.0017)$ and reduced the CGI Global Improvement Index $(p=0.0001, p=0.0006)$ compared to placebo. Mild adverse events were experienced by 4, 6, and 3 patients on placebo, IR, and MLR MPH, respectively.

Conclusions: MLR MPH given once daily produces equivalent improvements in behavioral and cognitive measures, and has a duration of effect at least as long as that of IR MPH given twice daily.
\end{abstract}

\section{INTRODUCTION}

I N THE 2002 EDITION OF THE PRACTICE parameters for the use of stimulant medication, the American Academy of Child and Adolescent Psychiatry (AACAP) recommend that children with moderate to severe impairment due to at- tention-deficit/hyperactivity disorder (ADHD) be considered for stimulant treatment (American Academy of Child and Adolescent Psychiatry 2002). In these practice parameters, the AACAP highlighted the need for long-duration formulations of methylphenidate (MPH) because clinicians have found that currently

\footnotetext{
${ }^{1}$ Hospital for Sick Children, Toronto, Ontario.

${ }^{2}$ Department of Psychology, University of Toronto, Toronto, Canada

${ }^{3}$ Adult Clinic Psychology at York University, Toronto, Ontario.

${ }^{4}$ Purdue Pharma, Pickering, Ontario.

This study was funded by Purdue Pharma (Canada).
} 
available long-duration products, such as Ritalin ${ }^{\circledR}$-SR and Metadate ${ }^{\circledR}$, are less effective than the short-acting versions. More recently, newer forms of controlled-release MPH (Concerta ${ }^{\circledR}$, Metadate ${ }^{\circledR}$ CD, Ritalin ${ }^{\circledR}$ LA $\left.^{\mathrm{TM}}\right)$, single-isomer $\mathrm{MPH}$ (Focalin $\left.{ }^{\mathrm{TM}}\right)$, controlled-release amphetamine (Adderall $\mathrm{XR}^{\circledR}$ ), and atomoxetine (Strattera $^{\mathrm{TM}}$ ) are available in the United States. Few of these products have been evaluated in Canadian patients, although since this study was conducted, Concerta ${ }^{\circledR}$, Strattera, and Adderall $\mathrm{XR}^{\circledR}$ have become available. Statistics from Health Canada data demonstrate a net increase in MPH consumption from 1982 to 1996, with a three-fold increase from 1993 to 1996 (Miller, 1999). Similar patterns of increased utilization have also been demonstrated in the United States and Australia (Miller 1999). The recently published Canadian ADHD/ADD Resource Alliance (CADDRA) guidelines recommend initiating treatment with one of the new ADHD products (Canadian ADHD Resource Alliance 2005).

Each of the new controlled-release MPH products was designed to deliver MPH at varying rates throughout the once-daily dosing interval (Patrick et al. 2005). The multilayer release (MLR) bead formulation of $\mathrm{MPH}$ (Biphentin ${ }^{\circledR}$ ) that was evaluated in this study was designed to provide both a rapid initial release of $\mathrm{MPH}(40 \%$ of the total MPH) followed by a delayed and more prolonged phase of release, resulting in a biphasic concentration-time profile that has been found to be effective in the treatment of child, adolescent, and adult ADHD (Jain et al. 2007; Weiss et al. 2007). In a single-dose pharmacokinetic study of healthy adult volunteers, this MLR formulation was fully bioavailable, relative to the immediate release (IR) formulation under fasted and fed conditions (Purdue Pharma 2006). The rate of increase in plasma MPH concentrations during the first 2 hours postdose with the MLR formulation was similar to that with the IR formulation. MPH release was prolonged in the MLR formulation, as evidenced by the higher plasma concentrations between 10 and 12 hours. These findings were confirmed in a single dose pharmacokinetic study in children with ADHD (Quinn et al, 2007). A comparison of the pharmacokinetics of MLR MPH and Concerta ${ }^{\circledR}$ showed higher plasma levels of methylphenidate in the first eight hours following dosing with MLR MPH, while maintaining comparable levels for the remainder of the day (Reiz et al. 2008)

The purpose of this study was to evaluate the comparative efficacy and pharmacodynamics of once-daily MLR MPH and IR MPH (Ritalin ${ }^{\circledR}$ ) in a randomized, double-blind, three-way crossover, placebo-controlled study in children with ADHD. In addition, the study was designed to compare the incidence and severity of MPH-related side effects and investigator assessments of efficacy and safety.

\section{METHOD}

This single-center, randomized, doubleblind, three-way cross-over, placebo-controlled study was conducted between September, 1999, and January, 2001, in accordance with ICH Good Clinical Practice Guidelines and the Declaration of Helsinki and was approved by a research ethics committee at the study site.

\section{Participants/subjects}

All patients gave written assent and all parents/guardians gave written informed consent prior to screening. Diagnostic and Statistical Manual of Mental Disorders, $4^{\text {th }}$ edition (DSMIV) diagnosis of ADHD (American Psychiatric Association 1994) was confirmed using the Schedule for Affective Disorders and Schizophrenia for School-Age Children-Present and Lifetime version (K-SADS-PL; Kaufman et al. 1997) and semistructured interviews with parents and teachers. Additional assessments included the Revised-Children's Manifest Anxiety Scale (RCMAS) (Reynolds and Paget 1983), the Children's Depression Inventory (CDI) (Kovacs 1992), the Clinical Evaluation of Language Fundamentals-3rd Edition (CELF-3) (Wiig et al. 1995) and the Wide Range Achievement Test-3rd Edition (WRAT-III) (Jastak and Wilkinson 1993). To be eligible, patients must have been 6-15 years of age with an intelligence quotient of 85 or greater on the Wechsler Intelligence Scales for Children (WISC-III) within the previous 12 months (Wechsler 1991). Subjects must have been mentally and physically competent to provide written informed consent 
with an ability to read, speak and understand English, and otherwise able to comply with the study protocol.

Patients were excluded if they were allergic to MPH or amphetamines or had a history of serious adverse reactions to MPH or had a lack of response to MPH. Nonresponse was defined as MPH use at various doses for a period of at least 4 weeks at each dose with little or no clinical benefit. Exclusion criteria included serious or unstable medical illness, co-morbid psychiatric illness of sufficient severity to require treatment, or currently receiving psychotropic medications or herbal treatments. Patients must not have had disorders of the sensory organs (particularly deafness), autism, psychosis, or any unstable psychiatric conditions.

\section{Design and procedures}

Patients received a total daily dose equal to approximately $1.2 \mathrm{mg} / \mathrm{kg}$ either as a single morning dose of MLR MPH (Biphentin ${ }^{\circledR}$, Purdue Pharma, Canada) with a placebo given as a lunch-time dose 4 hours apart, two equal doses of IR MPH (Ritalin ${ }^{\circledR}$, Novartis, Canada) $(0.6 \mathrm{mg} / \mathrm{kg}$ given twice at 9:00 a.m. and 1:00 p.m.) or matching placebos given as a morning dose and a lunch-time dose four hours apart.
Patients who were receiving $\mathrm{MPH}$ at the time of study entry received the dose of $\mathrm{MPH}$ that they were taking prior to entry into the study. Patients were randomly assigned to a treatment sequence according to a Latin square. Study medication was taken for a 1-week period followed by a full laboratory day of repeated psychometric and behavioral laboratory assessments. At the end of each laboratory day, patients were assessed with the Clinical Global Impressions (CGI) scale and were then crossed over to the next assigned treatment. Prior to each laboratory day, side effects were assessed using the Clinical Assessment of Side Effects (CASE) scale. Spontaneously reported adverse events were also collected during each laboratory day.

Cognitive and behavioral measures and adverse events were assessed over 8-10 hours in a laboratory setting following one week of dosing with each treatment. Table 1 lists the timing of activities occurring during each clinic visit. Study staff acted as informants for all measures.

\section{Measures}

Behavioral variables consisted of the Inattention/Overactivity with Aggression Conners

Table 1. Clinic Visit Activity Timetable

\begin{tabular}{|c|c|c|}
\hline Time & Hour & Activity \\
\hline 8:00 a.m. & -1 & CPT; Stop Task; IOWA-C; Problem Situations; Communicative Pragmatics \\
\hline \multirow[t]{3}{*}{ 9:00 a.m. } & 0 & Received first dose of study medication. \\
\hline & & Organized recreation activity. \\
\hline & & IOWA-C; Problem Situations; Communicative Pragmatics \\
\hline 10:00 a.m. & 1 & CPT; Stop Task; IOWA-C; Problem Situations; Communicative Pragmatics; arithmetic test \\
\hline 11:00 a.m. & 2 & $\begin{array}{l}\text { CPT; Stop Task; IOWA-C; Problem Situations; Communicative Pragmatics } \\
\text { Free recreation until lunch. }\end{array}$ \\
\hline 12:00 p.m. & 3 & Lunch in a controlled setting. \\
\hline \multirow{2}{*}{ 1:00 p.m. } & 4 & Received second dose of study medication. \\
\hline & & CPT; Stop Task; IOWA-C; Problem Situations; Communicative Pragmatics \\
\hline \multirow[t]{2}{*}{ 2:00 p.m. } & 5 & Organized recreation activity. \\
\hline & & IOWA-C; Problem Situations; Communicative Pragmatics \\
\hline \multirow[t]{2}{*}{ 3:00 p.m. } & 6 & CPT; Stop Task; IOWA-C; Problem Situations; Communicative Pragmatics \\
\hline & & \\
\hline \multirow[t]{2}{*}{ 4:00 p.m. } & 7 & CPT; Stop Task; IOWA-C; Problem Situations; Communicative Pragmatics \\
\hline & & Free recreation until 5:00 p.m. \\
\hline \multirow[t]{2}{*}{ 5:00 p.m. } & 8 & CPT; Stop Task; IOWA-C; Problem Situations; Communicative Pragmatics \\
\hline & & Free recreation until 6:00 p.m. \\
\hline \multirow[t]{2}{*}{ 6:00 p.m. ${ }^{\mathrm{a}}$} & 9 & Organized recreation activity. \\
\hline & & IOWA-C; Problem Situations; Communicative Pragmatics \\
\hline 7:00 p.m. ${ }^{\mathrm{a}}$ & 10 & CPT; Stop Task; IOWA-C; Problem Situations; Communicative Pragmatics \\
\hline
\end{tabular}

Abbreviations: CPT = Conners' Continuous Performance Task; IOWA-C = Inattention/Overactivity with Aggression-Conners.

aptional. 
scale (IOWA-C) (Loney and Milich 1982), the Child's Behaviour in Problem Situations scale (CBPS) (available from authors), and the Communicative Pragmatics scale (CP) (available from authors). All three scales are rated on a 4point scale $(0=$ "not at all", $1=$ "just a little", 2 = "pretty much," and $3=$ "very much"). The IOWA-C asks informants to rate 10 child problem behaviors, yielding two factor scores: inattentiveness/overactivity and aggressiveness. CBPS is a 7-item scale with which informants rate the extent of problem behavior when: "separating from parents," "during routine procedures," "while receiving instructions," "while completing tasks," "during play breaks," when "in hallway, bathroom or waiting room," and "during reunion with parents." The CP is a 10item scale with which informants rate the frequency of the following behaviors: "interrupts or talks over the clinician," "talks too much," "introduces unrelated/inappropriate topics/ comments," "difficult to follow child's line of thinking/conversation," "fails to respond or gives only minimal information," "inappropriate eye contact," "inappropriate facial expressions," "inappropriate body posture," "unclear speech/articulation," and "grammatical errors/immature language."

Cognitive variables consisted of the Stop Signal Paradigm (Stop Task) (Logan 1985; 1994; Logan et al. 1997), the Conners' Continuous Performance Task (CPT) (Conners 1995), and an arithmetic test. The Stop Signal paradigm is a sensitive measure of treatment effects in ADHD (Tannock et al. 1989). It involves two concurrent tasks, a Go Task and a Stop Task. The objective of the Go Task is to respond to a stimulus as quickly and accurately as possible. For the Stop Task, a stop signal occurs unpredictably on $25 \%$ of trials and involves presentation of a signal that instructs subjects to completely stop their response to the Go Task on that trial. A dynamic tracking strategy adjusts the delay between the onset of the Go and Stop signals, so that participants would be able to inhibit $50 \%$ of responses when given a stop signal. The stop signal reaction time (SSRT) is then calculated by subtracting the mean interval between the go signal and stop signal from the mean reaction time. A smaller SSRT indicates greater inhibitory control. The CPT is designed as a measure of sustained attention in children and has been described as being sensitive to medication effects. A meta-analysis of the effects of stimulants on the CPT concluded that it provides a quick, relatively inexpensive, objective measure of the impact of medications on at least some components of attention (Riccio et al. 2001). The arithmetic tests were tailored to an appropriate difficulty level for each subject and consisted of 60 addition, subtraction, or multiplication problems out of a possible 200. The number of questions attempted and number of questions correct was recorded.

The CGI, originally developed by the National Institute for Mental Health (NIMH), is a standard measurement tool that records an investigator's assessment of the improvement of a patient's condition or disease with respect to treatment, including therapeutic effect and severity of adverse events (National Institute for Mental Health 1976). The CGI measures global therapeutic effect, global adverse events, and a global improvement score. The CGI efficacy index is derived as the ratio of therapeutic/adverse effect. The CGI-Improvement (CGI-I) Scale is a 7-point scale that rates the behavioral changes in a patient receiving treatment, ranging from "very much improved" (1) to "very much worse" (7). The CGI-Severity scale was not used.

Safety variables included spontaneous reports of adverse events and the CASE (available from authors). This instrument consists of a series of 26 possible adverse events common to stimulant medications and one "other" category. The occurrence and severity of these adverse events in patients were rated separately by both teachers and parents, using a zero-tonine scale $(0=$ "none," 1 to $3=$ "mild," 4 to $6=$ "moderate," and 7 to $9=$ "extreme"). The Physician-Assisted Assessment of Child's Satisfaction (PAACS) questionnaire was used to assess the patient's satisfaction with each of the treatments and an investigator assessment of medical compliance was conducted.

\section{Statistical analysis}

On the basis of a review of the ADHD literature, it was determined that a clinically mean- 
ingful difference between pre-treatment and treatment scores on the IOWA-C or CPT was at least $40 \%$. The required sample size was 16 patients, assuming a coefficient of variation of $70 \%$, an intrapatient correlation of 0.5 and a within-patient comparison for a two-tailed test of significance where $\alpha=0.05$ and $\beta=0.20$ (80\% power). Only patients with efficacy data from all three phases were evaluated for efficacy. All patients receiving test medication were evaluated for safety.

The mean scores from the Stop Task, CPT, IOWA-C, CBPS, and CP scales were compared between the three treatment groups using analysis of covariance with predose scores at the corresponding visit as the covariate. Because prephase scores varied considerably between visits and, if not accounted for, would have biased the comparisons between treatments, confirmatory statistics were conducted using predose scores from each visit as covariates to adjust for treatment effects in the analysis model. All outcome variables were tested for carryover effect. If carryover was detected, a first-order carryover was tested for and, if that was also significant, then the data were to be analyzed for phase one only. The patientwithin-sequence variance was used as the error term for testing sequence. Pair-wise contrasts were constructed to compare treatments, using a within-patient variance structure. To test for change over time, multivariate repeated-measures analysis of variance of change scores was conducted.

The arithmetic test, PAACS, CGI, and CASE results were analyzed using three-way analysis of variance (ANOVA) of the mean score and the difference in scores within the day. Pairwise contrasts were used for treatment comparisons. The Investigator Assessment of Medical Compliance rating was compared by treatment using pair-wise McNemar's chisquare tests. All adverse events were coded (COSTART IV) using preferred terms to standardize the terminology. McNemar's test was used to determine the significance of differences in overall frequency of side effects between the treatments. Statistical significance was defined as $p<0.05$ for a two-tailed hypothesis.

\section{RESULTS}

\section{Patient disposition}

Of the 18 patients enrolled in the study, 17 completed all 3 weeks of treatment. One patient discontinued due to an inability to swallow the capsules. All patients enrolled who had data from all three treatment phases and did not have major protocol violations were considered evaluable for efficacy; all patients were evaluated for safety. The mean age of the patients was $11.3 \pm 2.2$ years (range 6.815.3 years) old and included 15 boys and 2 girls. The average dose of study medication was $31.2 \pm 11.7 \mathrm{mg} /$ day (range 20-60 mg/ day). Of the 17 evaluable patients, 5 (29.4\%) were not taking $\mathrm{MPH}$ immediately prior to the study and $12(70.6 \%)$ were taking MPH. Patients enrolled in the study did not have comorbidities. Patients were diagnosed as ADHD combined-type.

\section{Cognitive measures}

Stop Task. Significant differences were observed between the mean scores across all time points on the Stop Signal Reaction Time for both MLR and IR MPH compared to placebo (Table 2), with no differences between the two active treatments on any of the variables. Confirmatory statistics showed MLR and IR MPH were not significantly different $(p=0.5771)$ and both were superior to placebo $(p=0.0065$ and $p=0.0252$, respectively). The time-course effects of the Stop Signal Reaction Time are depicted in Fig. 1. There was no significant effect by time $(p=0.8199)$.

Continuous performance test. Significant differences were observed between the mean scores across all time points in Errors of Omission for each of the treatment groups compared to placebo (Table 2). Confirmatory statistics showed MLR and IR MPH were not significantly different $(p=0.6301)$ and were superior to placebo $(p=0.0001$ and $p=$ 0.0002 , respectively). However, there were no significant differences observed between the mean scores across all time points for Errors of Commission for each of the treatment groups compared to placebo. The two treat- 


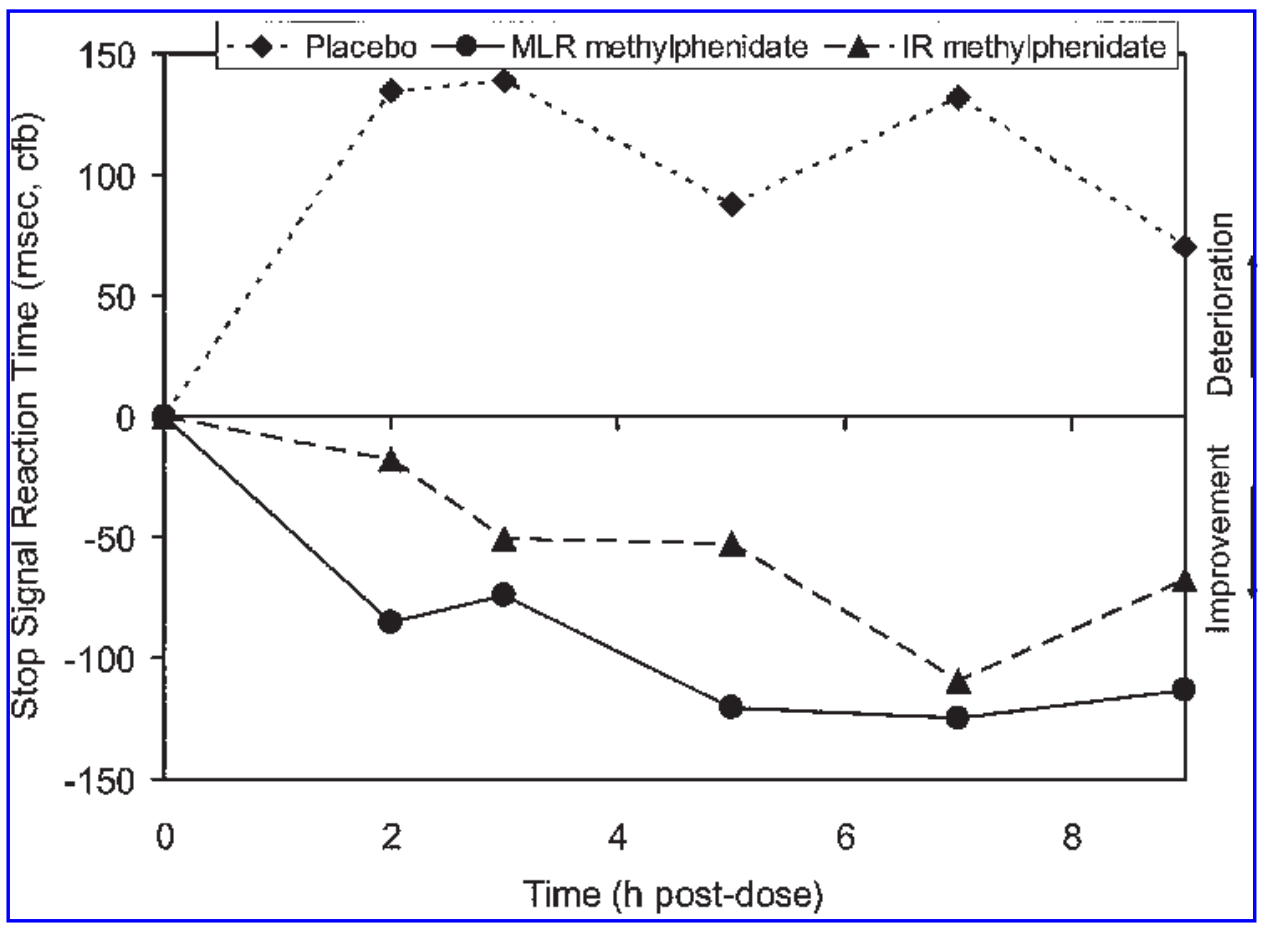

FIG. 1. Cognitive Assessments-Stop Signal Reaction Time. Improvement was defined as faster reaction time than that at baseline. MLR = Multilayer-release; IR = immediate-release; $\mathrm{cfb}=$ change from baseline.

ments did not differ for either of the two measures. Confirmatory statistics showed MLR and IR MPH were not significantly different $(p=0.1120)$ and MLR, but not IR, MPH, was significantly different from placebo $(p=$ 0.0411 and $p=0.6047$, respectively). Timecourse effects of the Errors of Omission were significant and are depicted in Fig. $2(p=$ 0.0254).

Arithmetic test. There were significant differences compared to placebo in two of the three measures for each of the two active treatments (Table 2) with no significant between treatment differences.

Table 2. Mean (SD) Cognitive Measures for Placebo, IR, and MLR Methylphenidate

\begin{tabular}{|c|c|c|c|}
\hline Measure & $\begin{array}{c}\text { Placebo } \\
\text { mean (SD) }\end{array}$ & $\begin{array}{c}\text { IR methylphenidate } \\
\text { mean (SD) }\end{array}$ & $\begin{array}{c}M L R \\
\text { methylphenidate } \\
\text { mean (SD) }\end{array}$ \\
\hline \multicolumn{4}{|l|}{ Stop task } \\
\hline Go task (msec) & $721.8(220.1)$ & $670.9(195.3)^{\mathrm{a}}$ & $673.1(183.5)$ \\
\hline Mean delay (msec) & $349.6(219.6)$ & $409.3(210.8)$ & $426.1(218.0)^{\mathrm{b}}$ \\
\hline Stop signal reaction time (msec) & $372.2(167.8)$ & $261.6(146.1)^{b}$ & $247.1(106.4)^{\mathrm{b}}$ \\
\hline \multicolumn{4}{|l|}{ Continuous Performance Test } \\
\hline Errors of omission $(n)$ & $60.0(41.5)$ & $31.0(26.6)^{b}$ & $47.7(50.9)^{\mathrm{b}}$ \\
\hline Errors of Commission $(n)$ & $24.1(5.4)$ & $25.6(5.8)$ & $24.5(6.4)$ \\
\hline \multicolumn{4}{|l|}{ Arithmetic test } \\
\hline Number completed & $22.9(5.5)$ & $26.0(13.8)^{\mathrm{a}}$ & $25.2(10.6)$ \\
\hline Number correct & $17.6(9.1)$ & $20.7(13.3)^{\mathrm{a}}$ & $20.5(9.7)^{\mathrm{a}}$ \\
\hline Percent correct & $75.8(19.8)$ & $77.5(14.7)$ & $81.2(14.1)^{\mathrm{a}}$ \\
\hline
\end{tabular}

Abbreviations: $\mathrm{SD}=$ Standard deviation; $\mathrm{IR}=$ immediate release; $\mathrm{MLR}=$ multilayer release.

$p$ Values are vs. placebo.

Data are averaged from all postdose data points across the clinic day.

a $p<0.05$.

$\mathrm{b}_{p}<0.01$. 


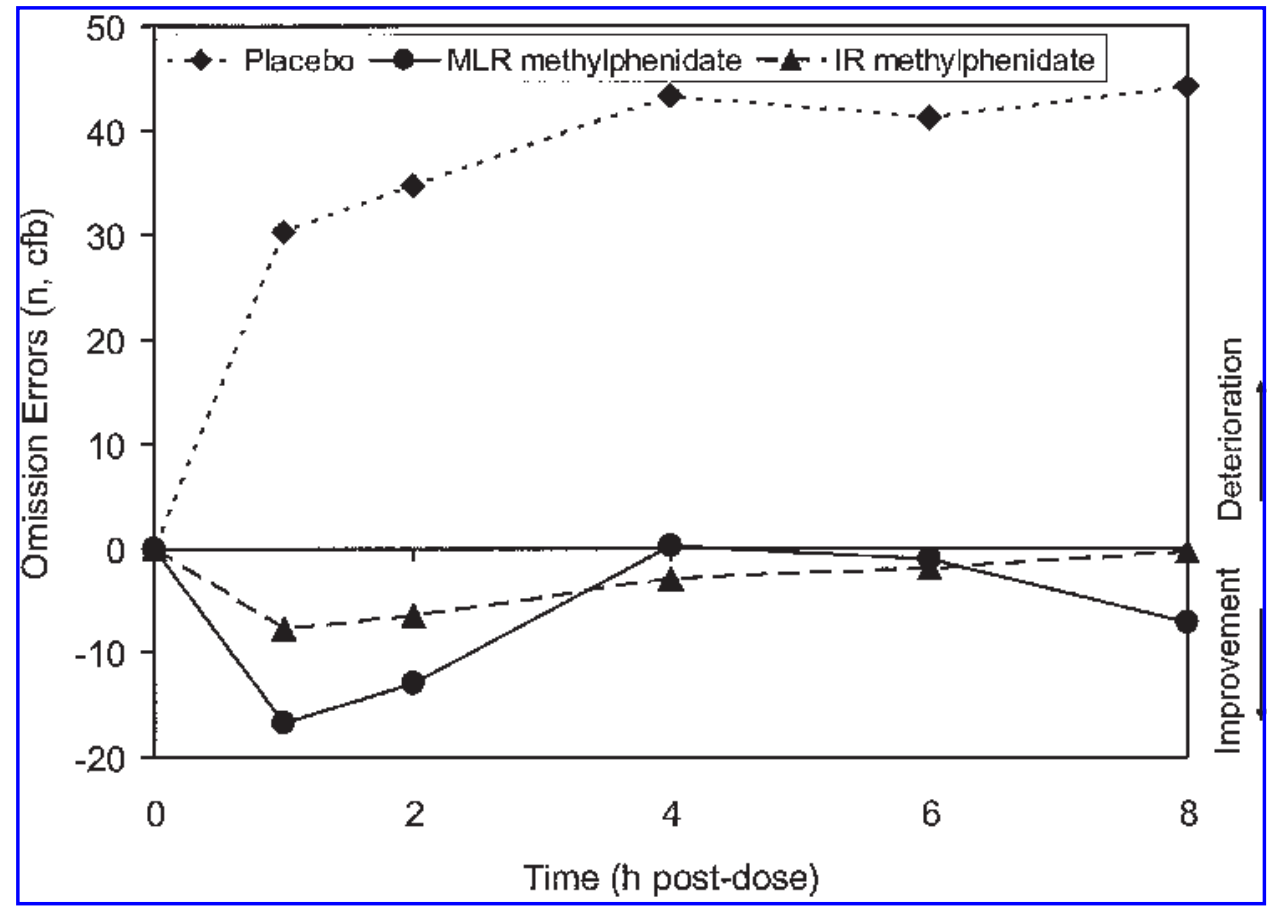

FIG. 2. Cognitive Assessments - Continuous Performance Task: Errors of Omission. Improvement was defined as a decrease in the number of omission errors than at baseline measurement. MLR = Multilayer-release; IR $=$ immediate-release; $\mathrm{cfb}=$ change from baseline.

\section{Behavioral measures}

IOWA-C. The changes from pre-dose mean IOWA-C scores across all time points are presented in Table 3. Because hour 0 baselines were not the same at each clinic visit, change from predose is presented in the tables and figures to allow for easiest comparison between groups. Actual values of the IOWA/C Overall Score for MLR MPH treatment were $3.09 \pm 2.90$ for baseline and $1.71 \pm 2.39$ for mean treated score $(44.7 \%$ decrease). Baseline was $1.47 \pm$ 2.29 and mean treated score was $0.86 \pm 0.50$ for IR MPH treatment ( $41.5 \%$ decrease). For placebo, baseline was $1.38 \pm 1.91$, and mean treated score was $3.42 \pm 2.62$ (147.8\% increase). Significant differences were observed in the overall IOWA-C and the Inattention/Overactivity subscale for both MLR and IR MPH compared to placebo. Confirmatory statistics showed MLR and IR MPH were not significantly different $(p=0.6155)$ and were superior

Table 3. Means (SD) Behavioral Measures for Placebo, IR, and MlR Methylphenidate

\begin{tabular}{lccc}
\hline $\begin{array}{l}\text { Measure } \\
\text { (change from predose) }\end{array}$ & $\begin{array}{c}\text { Placebo } \\
\text { mean (SD) }\end{array}$ & $\begin{array}{c}\text { IR methylphenidate } \\
\text { mean (SD) }\end{array}$ & $\begin{array}{c}\text { MLR methylphenidate } \\
\text { mean (SD) }\end{array}$ \\
\hline IOWA-C & & & $-1.38(2.27)^{\mathrm{b}}$ \\
$\quad$ Overall & $2.03(2.39)$ & $-0.66(2.05)^{\mathrm{b}}$ & $-1.26(1.97)^{\mathrm{b}}$ \\
$\quad$ Inattention/Overactivity subscale & $3.20(2.82)$ & $-0.98(2.14)^{\mathrm{b}}$ & $-1.5(2.82)$ \\
$\quad$ Aggression/Defiance subscale & $0.86(2.37)$ & $-0.33(2.08)^{\mathrm{a}}$ & $-0.47(1.52)^{\mathrm{a}}$ \\
Problem situations & $1.49(1.98)$ & $-0.35(1.06)^{\mathrm{b}}$ & $-0.89(3.25)$ \\
Communicative pragmatics & $2.91(4.00)$ & $-0.27(3.14)$ & \\
\hline
\end{tabular}

Abbreviations: $\mathrm{SD}=$ Standard deviation; IR = immediate release; MLR = multilayer release; IOWA-C $=$ Inattention/Overactivity with Aggression-Conners.

$p$ Values are vs. placebo (negative scores indicate improvement).

Data are averaged from all postdose data points across the clinic day.

${ }^{\mathrm{a}} p<0.05$.

$\mathrm{b}_{p}<0.01$ 
to placebo $(p=0.0001$ and $p=0.0001$, respectively). The time-course effects for the Inattention/Overactivity subscale were significant and are depicted in Fig. 3a and show deterioration of behavior during the day with placebo and maintenance of effect for both MLR MPH and IR MPH ( $p=0.0022)$. Both MLR MPH and IR MPH produced significant improvements in behaviour on the IOWA-C Inattention/Overactivity subscale after 1 hour of treatment com-
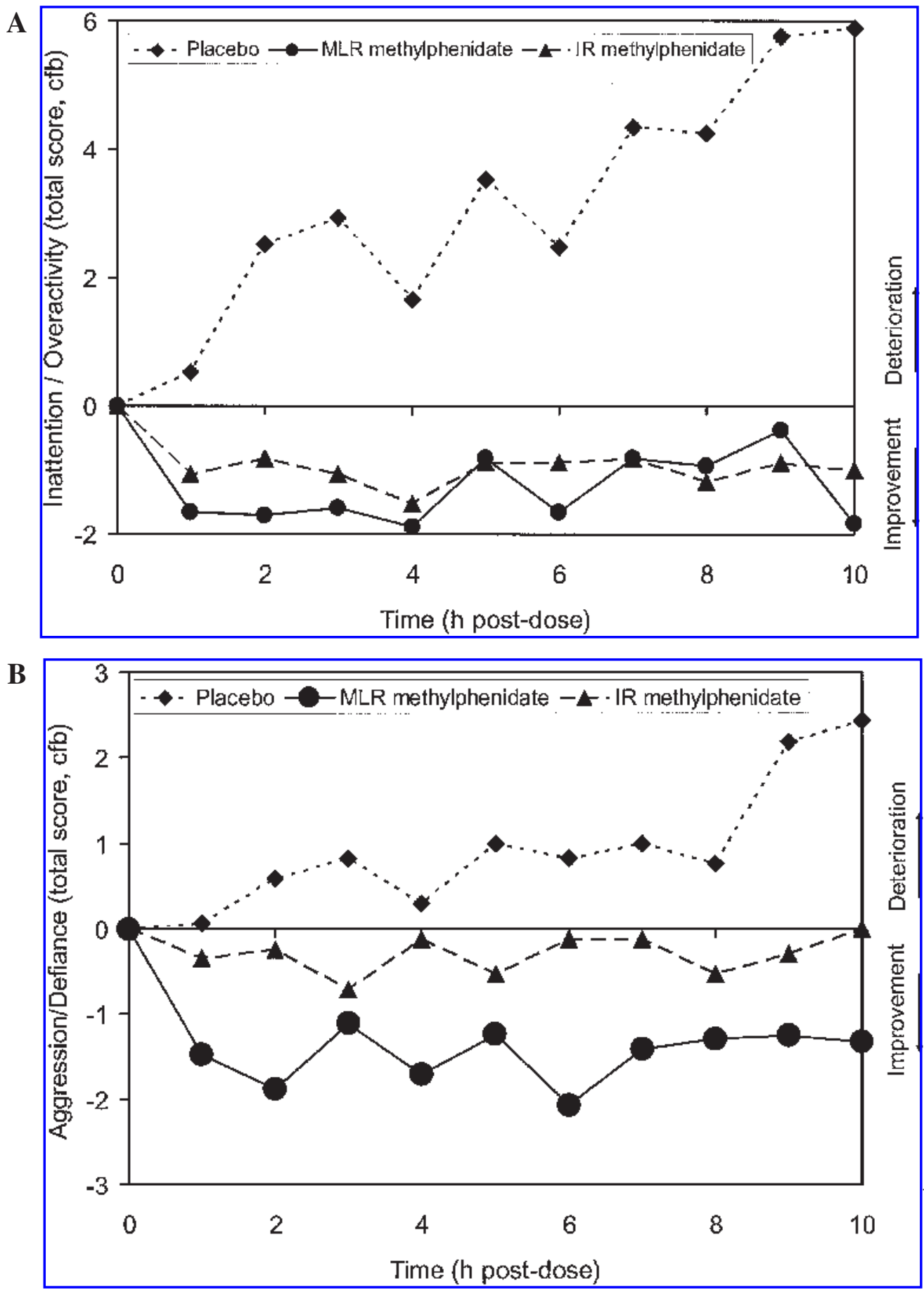

FIG. 3. Behavioral Assessments-IOWA/C. Improvement was defined as a decrease in the total score of the appropriate subscale than at baseline measurement, as measured by the Investigator. (A) Inattention/Overactivity subscale. (B) Aggression/Defiance subscale. MLR = Multilayer-release; IR = immediate-release; $\mathrm{cfb}=$ change from baseline. At each time point following hour 0, cfb MLR and IR methylphenidate scores were significantly different from cfb placebo scores $(p<0.05)$. 
pared to predose ( $p=0.0299$ and 0.0428$)$. Timecourse effects were not significant for the IOWA-C Aggression/Defiance subscale ( $p=$ $0.1629)$, although significant differences were observed compared to placebo for IR MPH, but not MLR MPH (Fig. 3b). However, confirmatory statistics showed only MLR, and not IR $\mathrm{MPH}$, was superior to placebo ( $p=0.0063$ and $p=0.1654$, respectively) and both active treatments were not significantly different $(p=$ 0.1407). Improvements in behavior with MLR $\mathrm{MPH}$ and IR MPH did not differ on any subscale.

Child's behaviour in problem situations. The time course effects of improvement in the Child's Behaviour in Problem Situations mirrors that of the IOWA-C, Stop Task, and the CPT. There were significant differences between placebo and the two active treatments in the mean scores across all time points with no significant differences between treatments (Table 3). Confirmatory statistics showed MLR and IR MPOH were not significantly different $(p=0.7622)$ and both were superior to placebo $(p=0.0005$ and $p=0.0010$, respectively).

Communicative pragmatics. There was a significant carryover effect detected $(p=0.0260)$ for the mean scores across all time points. Since this was a three-way crossover, the first-order carryover effect was also calculated and was found to be significant $(p=0.0042)$. Analysis of only phase 1 data showed no statistically significant differences between treatments (Table 3). Confirmatory statistics showed MLR and IR $\mathrm{MPH}$ were not significantly different $(p=$ $0.7527)$ and were superior to placebo ( $p=$ 0.0009 and $p=0.0016$, respectively).

\section{Overall efficacy}

Clinical Global Impressions. A total of $76.5 \%$, $58.8 \%$, and $17.6 \%$ of patients were rated as "much improved" or "very much improved" on the Global Improvement subscale on MLR $\mathrm{MPH}, \mathrm{IR} \mathrm{MPH}$, and placebo, respectively. The treatment effect differences between MLR $\mathrm{MPH}$ and placebo and IR MPH and placebo were significant on the Therapeutic Effect and Global Improvement subscales of the CGI $(p<$ $0.001)$ with no differences in active treatments $(p>0.23)$. No differences were found between any treatments on the Adverse Effect subscale $(p>0.30)$. The Efficacy Index subscale (therapeutic effects $\div$ adverse events) was significantly improved on both MLR and IR MPH treatment compared to placebo $(p=0.0001)$, with no differences in active treatments $(p=$ 0.10) (Fig. 4).

Physician Assisted Assessment of Child's Satisfaction. No significant differences were observed between treatments in any parameters of the PAACS, except for "children's assessment of how well each of the treatments controlled their behavior" (MLR MPH vs. placebo, $p=0.0082$; IR MPH vs. placebo, $p=0.0007$; MLR MPH vs. IRMPH , $p=0.3487)$.

\section{Investigator assessment of medication compliance}

The investigator rated the compliance level of each patient during each period, including all nonclinic-visit days. The percent of patients rated as having perfect compliance during MLR MPH, IR MPH, and placebo phases were $82.4 \%, 82.4 \%$, and $64.7 \%$, respectively. There was no significant difference in compliance level between MLR MPH and placebo $(p=$ $0.317)$ or IR MPH and placebo $(p=0.257)$ or between active treatments $(p=1.00)$.

\section{Safety}

There was no significant difference in the mean CASE global rating between MLR MPH and placebo $(p=0.2960)$ or IR MPH and placebo $(p=0.2041)$ or between active treatments $(p=0.8161)$. Few events were reported on the CASE on MLR MPH, IR MPH, and placebo treatment: "sleep problems" were noted in 2, 2, and 3 patients, respectively; "headaches" were noted in 3, 5, and 2 patients, respectively; "nausea" was noted in 2, 1, and 2 patients, respectively; "irritability" was noted in 1, 2, and 1 patient, respectively; and "sombre, serious, unhappy" was noted in 0,2 , and 0 patients, respectively. No other event was noted in greater than 1 patient. In addition, there were very few spontaneous adverse events reported and none of them was serious. The number of patients reporting events during MLR MPH, IR MPH, and placebo were 3, 6 , and 4 respectively (Table 4 ). 


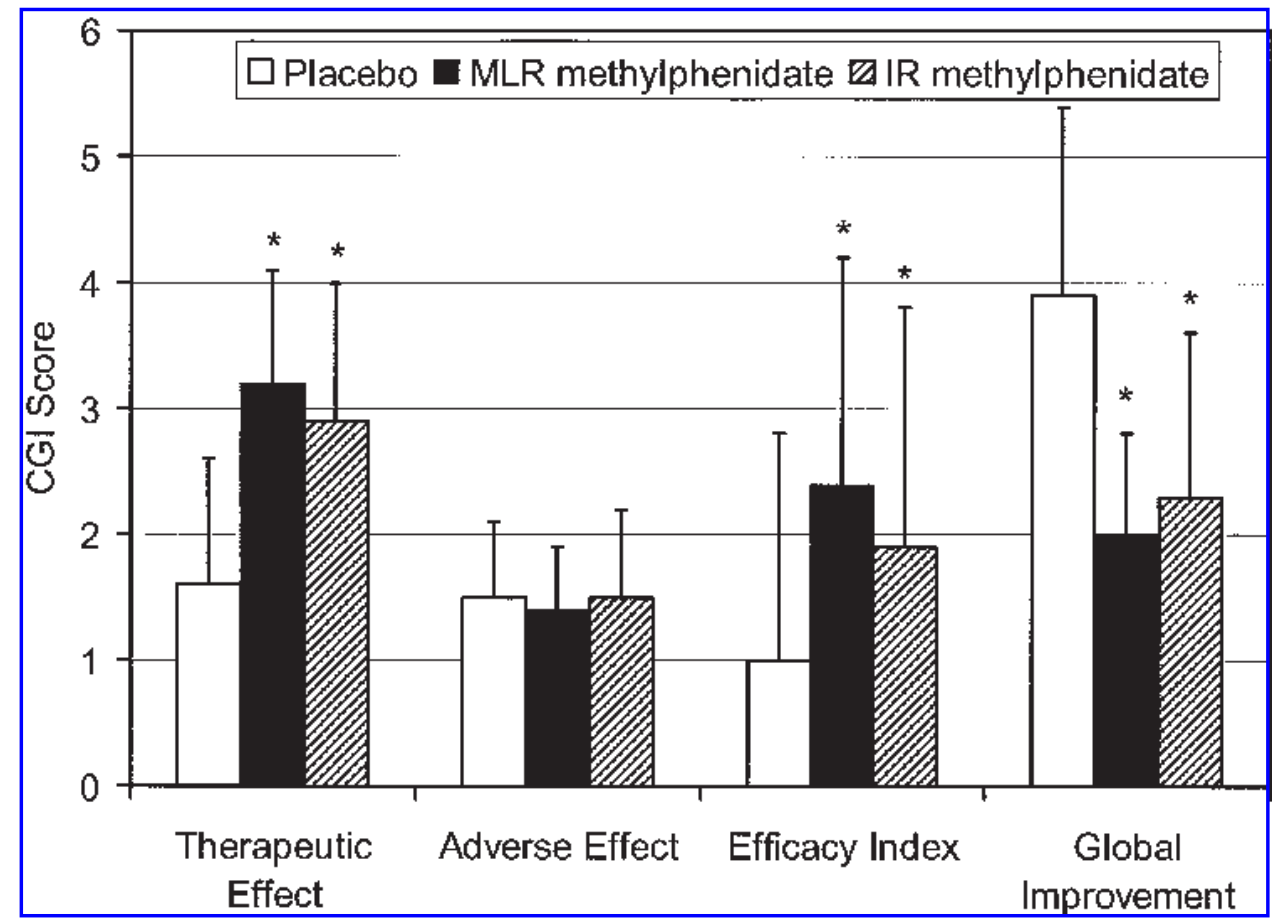

FIG. 4. Clinical Global Impressions. Therapeutic Effects scale: $1=$ none, $2=$ mild, $3=$ moderate, $4=$ severe-extreme; Adverse Effects scale: $4=$ marked, $3=$ moderate, $2=$ minimal, $1=$ unchanged. Efficacy Index $=$ therapeutic effect $\div$ adverse effects. Global Improvement scale: $1=$ very much improved; $2=$ much improved; $3=$ minimally improved; $4=$ no change; $5=$ minimally worse; $6=$ much worse; $7=$ very much worse. ${ }^{*} p<0.001$ versus placebo. MLR $=$ Multilayer-release; IR = immediate-release.

\section{DISCUSSION}

In this laboratory classroom-based study, the first clinical trial in children with ADHD of a once-daily MPH formulation (Biphentin ${ }^{\circledR}$ ) using MLR beads, both MLR MPH and IR MPH produced significant improvements from placebo on both behavioral and cognitive evaluations.
The ability of MPH to improve a child's behavior has been well documented (National Institute of Mental Health 1976; American Academy of Pediatrics 2001; American Academy of Child and Adolescent Psychiatry 2002). In this study, both MLR MPH and IR MPH demonstrated significant improvement compared to placebo on the IOWA-C average total score with an onset of action observable by 1 hour.

Table 4. Incidence of Spontaneous Adverse Events during Clinic Visits

\begin{tabular}{|c|c|c|c|c|}
\hline Body system & Adverse event & $\begin{array}{c}M L R \text { methylphenidate } \\
(\mathrm{n})\end{array}$ & $\begin{array}{l}\text { IR methylphenidate } \\
(\mathrm{n})\end{array}$ & $\begin{array}{l}\text { Placebo } \\
\text { (n) }\end{array}$ \\
\hline Body as a whole & Headache & 1 & 1 & 1 \\
\hline Central nervous & Tremor & & 1 & 1 \\
\hline \multirow[t]{3}{*}{ System } & Somnolence & 1 & 1 & \\
\hline & Asthenia & 1 & & \\
\hline & Psychosis & & & 1 \\
\hline Digestive & Anorexia & & 1 & \\
\hline \multirow[t]{2}{*}{ Respiratory } & Rhinitis & & 1 & \\
\hline & Infection & & & 1 \\
\hline Skin and appendages & Pruritus & & 1 & \\
\hline
\end{tabular}

Abbreviations: $\mathrm{MLR}=$ multilayer release; $\mathrm{IR}=$ immediate release. 
Interestingly, children's behavior tended to worsen while on placebo, as shown by an increase in behavioral scores, such as the IOWA$\mathrm{C}$ average total score, as the day progressed. In contrast, children's behavior while on MLR $\mathrm{MPH}$ or IR MPH displayed an initial improvement, subsequently remaining constant over time. These results indicate that ADHD symptoms are somewhat mild in the morning and increase in severity throughout the day and confirm previous findings (Pelham et al. 2001; Lopez et al. 2003). Both MLR MPH and IR MPH prevented this behavioral deterioration but placebo did not. A similar trend was observed with the Inattention/Overactivity subscale, and both MLR MPH and IR MPH produced significant improvement compared to placebo.

The Aggression/Defiance subscale of the IOWA-C may be related to oppositional behavior, and observed improvement was not as significant as with the other subscale. Because of the demands of the study, which required extensive testing over a period of 3 lengthy laboratory days, children with less oppositional behavior may have been more likely to be selected as appropriate candidates. When baseline values were controlled for, significant improvement was observed with both MLR and IR MPH treatment in comparison to placebo. In addition, behavioral improvements were demonstrated for both MLR MPH and IR MPH as measured by The Child's Behaviour in Problems Situations scale, where the difference between and MLR MPH and IR MPH was not significant. MLR MPH not only improves a child's behavior in normal everyday situations but also in potentially problematic situations, such as during play breaks or when being instructed to comply with a task.

If improving a child's behavior during the course of a school day is the primary reason parents seek treatment for their ADHD children, then improvements in cognitive function, such as increased attention and academic performance are important secondary outcomes. In addition to improvements in behavior, both MLR MPH and IR MPH treatment improved cognitive functioning in this study. The CPT is a widely used cognitive task that measures patient attention and has been shown to be sensitive to MPH treatment effects in children with
ADHD (Pelham et al. 1987; Pelham et al. 1990; Riccio et al. 2001). Previous studies have shown improvements in commission and/or omission errors in children with ADHD treated with MPH (Aman et al. 1987; Aman et al. 1991; Losier et al. 1996). In this study following MPH treatment, the number of omission errors dropped significantly compared to placebo, whereas the number of commission errors, or false positives, remained constant. In addition, treatment with $\mathrm{MPH}$ led to improvements in inhibitory control on the Stop Task. False positives in the CPT are typically considered a measure of impulse control and omission errors, which reflect sustained attention, are deemed to be less reliable (Epstein et al. 2003). Medication-related improvement on omission error rate but not on rate of false positives may indicate that when medicated, participants adopted a more conservative approach, slowing their response time and reducing omission errors, but not rate of false positives.

Along with improvement in cognitive measures of attention and inhibition, academic performance with both MLR MPH and IR MPH treatments showed improved productivity compared to placebo in this study, despite historical evidence that suggests MPH therapy has demonstrated a modest or lack of effectiveness in enhancing academic achievement (National Institute of Mental Health 1976; American Academy of Pediatrics 2001; American Academy of Child and Adolescent Psychiatry 2002). Although the gains were small, MPH improved academic performance by increasing productivity, or the speed and accuracy of the child's performance, possibly by reducing distractibility or increasing attention.

The CGI has proved to be a reliable and sensitive measure of efficacy in drug treatment trials of psychiatric patients. Not only was significant improvement observed with MLR $\mathrm{MPH}$ as measured by the Therapeutic Effect and Global Improvement scales, but also the risk did not outweigh the benefit since the score on the Efficacy Index scale was higher for MLR $\mathrm{MPH}$ than placebo, indicating an acceptable profile.

For overall assessment of medication efficacy, two global measures, the CGI and the Physician Assisted Assessment of Child's Sat- 
isfaction, provide a broader perspective than more specialized cognitive and behavioral measures. Both scales take into account how well the medication is working in a variety of situations both cognitively and behaviorally. When completing the CGI, the physician takes into account feedback received from the teacher (or in this study a qualified evaluator), the parent, the child, direct observation in the clinic as well as professional judgement, resulting in a well-balanced and comprehensive evaluation. The results from the Physician Assisted Assessment of Child's Satisfaction scale demonstrated that the benefit from MPH was both recognized and appreciated by the children who participated in this study.

Despite differences in expected plasma concentration profiles in the morning and late afternoon, MLR MPH and IR MPH were equivalent throughout the day. For example, the time-course effects of the Stop Signal Reaction Time and CPT errors of omission demonstrate deterioration over time for placebo and maintenance of effect for both MLR MPH and IR $\mathrm{MPH}$. At no time point did the efficacy of IR $\mathrm{MPH}$ decline, such as immediately prior to the second dose or late in the day when the effects were expected to have worn off. MLR MPH does not exhibit a ramp profile, and yet its effects do not appear to diminish over time, indicating that tachyphylaxis does not occur. Improved behavior in response to MPH may be more complex than a simple reflection of plasma levels or the occurrence of tachyphylaxis. Optimizing plasma concentrations in individual patients appears to be more relevant as a determinant of response than delivering a specific concentration-time profile, such as an "ascending ramp" of MPH plasma levels (Swanson et al. 2004; Patrick et al. 2005).

There are currently three second-generation controlled-release MPH formulations on the U.S. market, but only one at the time of writing, OROS MPH (Concerta ${ }^{\circledR}$ ), is approved in Canada. Each uses a proprietary system to control the release of MPH. The ideal once-daily $\mathrm{MPH}$ product has a rapid onset, an overall absorption corresponding to peak activities during periods in the child's day when control is most needed (at school and during homework), minimizes lunchtime appetite suppression by offering a $\mathrm{MPH}$ plasma trough around noon and allows for a normal dinner appetite and sleep schedule (Markowitz et al. 2003).

To attempt to address all of these requirements, MLR MPH uses MLR technology beads, whereby $40 \%$ of the total amount of MPH is delivered immediately and $60 \%$ is subsequently delivered in a controlled release within a singlebead formulation, whereas OROS MPH uses the OROS system combined with an IR overcoat, which delivers $22 \%$ of the total available $\mathrm{MPH}$, with the remaining $78 \%$ being slowly released over a 12-hour period in an ascending ramp (Patrick et al. 2005). The design of OROS MPH is argued to offset the effect of rapidly developing tachyphylaxis (Swanson et al. 1999). However, the clinical significance of tachyphylaxis as pertaining to $\mathrm{MPH}$ response remains theoretical in nature (Patrick et al. 2005), and was not shown to be an issue during the conduct of this study. For MLR MPH, the result is a moderately biphasic profile that provides an initial maximum concentration of approximately $80 \%$ of that obtained with the first dose of IR MPH at approximately the same time, together with significantly higher concentrations at hour 12 . Based upon this profile, MLR MPH will provide morning efficacy approaching that of IR MPH and a duration of action that persists up to 12 hours, without having to administer a total daily dose of $\mathrm{MPH}$ that is greater than equivalent doses of IR MPH (Swanson and Volkow 2002; Swanson et al. 2004).

\section{Limitations}

Although this study was relatively small in size, previous studies have shown that treatment effects of MPH can be demonstrated with relatively few patients (Pelham et al. 1987; Pelham et al. 1990). This is particularly true with the crossover design employed in the current study. Conclusions were based on change from predose values, as there were differences in baseline values by phase. Last, conclusions that can be drawn from this study may be limited by the structured setting, although quite similar to that encountered in classrooms, which may not reflect behaviors in less controlled environments, such as the expected advantages of once-daily dosing on compliance. 


\section{Clinical implications}

This study demonstrated that both oncedaily MLR MPH and IR MPH given in divided doses are extremely effective and tolerable medications for the treatment of ADHD. Both active treatments produced efficacy that persisted for at least 10 hours, which would encompass an entire school day and the postschool homework period time. Although the pharmacokinetic profile of MLR MPH is consistent with such a duration-of-action, the finding that IR MPH was still effective at 10 hours was surprising.

These findings were obtained in a very controlled setting and are more likely to be replicated in routine clinical use with once-daily MLR $\mathrm{MPH}$ than with the IR preparation because parents would have the opportunity to supervise administration of the total daily dose prior to the child leaving home. Although MLR MPH did not demonstrate superiority to IR MPH, it appears to have addressed the issue of slow onset often seen with controlled-release MPH products, while still providing a long duration of action. Together with its favorable side effect profile, it has the potential to improve compliance and treatment outcomes in routine clinical use.

\section{DISCLOSURES}

Drs. Schachar and Ickowicz have no conflicts of interest or financial ties to report. Dr. Crosbie has no conflict of interest or financial ties to report. Ms. Miceli was an employee of Purdue Pharma when this research was conducted. Mr. Reiz, Mr. Harsanyi and Mr. Donnelly are employees of Purdue Pharma, Pickering, Ontario. Dr. Darke was an employeee of Purdue Pharma when this research was conducted. The statistical analysis plan was written by Dr. Schachar and Mr. Harsanyi and statistical analysis was completed by Mr. Harsanyi. All authors collaborated on the project design or written manuscript.

\section{REFERENCES}

Aman MG, Marks RW, Turbott SH, Wilsher CP, Merry $\mathrm{SN}$ : Methylphenidate and thioridazine in the treatment of intellectually subaverage children: Effects on cognitive-motor performance. I Am Acad Child Adolesc Psychiatry 30:816-824, 1991.

Aman MG, Werry JS, Paxton JW, Turbott SH: Effects of sodium valproate on psychomotor performance in children as a function of dose fluctuations in concentration and diagnosis. Epilepsia 28:115-124, 1987.

American Academy of Child and Adolescent Psychiatry: Practice parameter for the use of stimulant medications in the treatment of children, adolescents, and adults. I Am Acad Child Adolesc Psychiatry 41:26S-49S, 2002.

American Academy of Pediatrics: Clinical practice guideline: Treatment of the school-aged child with attentiondeficit/hyperactivity disorder. Pediatrics 108:10331044, 2000.

American Psychiatric Association: Diagnostic and statistical manual of mental disorders, $4^{\text {th }}$ edition (DSM-IV). Washington (DC). American Psychiatric Association, 1994, pp 75-85.

Canadian ADHD/ADD Resource Alliance (CADDRA) Guidelines Steering Committee: Guidelines for the diagnosis and management of ADHD, $1^{\text {st }}$ edition. Toronto, Canadian ADD Resource Alliance, 2005.

Conners CK: Conners' Continuous Performance Test. Ottawa: MultiHealth Systems, 1995.

Epstein JN, Erkanli A, Conners CK, Klaric J, Costello JE, Angold A: Relations between Continuous Performance Test performance measures and ADHD behaviours. I Abnorm Child Psychol 31:543-554, 2003.

Jain U, Hechtman L, Weiss M, Ahmed TS, Reiz JL, Donnelly GA, Harsanyi Z, Darke AC: Efficacy of a novel biphasic controlled-release methylphenidate formula in adults with attention-deficit/hyperactivity disorder. J Clin Psychiatry 68:268-277, 2007.

Jastak S, Wilkinson GS: The Wide Range Achievement Test, $3^{\text {rd }}$ edition: Administration Manual. Wilmington (Delaware), Jastak Associates, 1993.

Kaufman J, Birmaher B, Brent D, Rao U, Flynn C, Moreci P, Williamson D, Ryan N: Schedule for Affective Disorders and Schizophrenia for School-Age ChildrenPresent and Lifetime Version (K-SADS-PL): Initial reliability and validity data. I Am Acad Child Adolesc Psychiatry 36:980-988, 1997.

Kovacs M: Children's Depression Inventory Manual. Toronto: Multi-Health Systems, 1992.

Logan GD: On the ability to inhibit simple thoughts and actions: II stop-signal studies of repetition priming. J Exp Psychol 11:675-691, 1985.

Logan GD: On the ability to inhibit thought and action: A users' guide to the stop signal paradigm. In: Inhibitor Processes in Attention, Memory, and Language. Edited by Dagenbach D, Carr TH. San Diego, Academic Press, 1994, pp 189-239.

Logan GD, Schachar RJ, Tannock RT: Impulsivity and inhibitory control. Psycholog Sci 8:60-64, 1997.

Loney J, Milich R: Hyperactivity, inattention, and aggression in clinical practice. In: Advances in Developmental and Behavioural Pediatrics. Edited by Wolraich M, Routh D. Greenwich Connecticut), JAI, 1982, pp 113-147. Lopez F, Silva R, Pestreich L, Muniz R: Comparative ef- 
ficacy of two once daily methylphenidate formulations (Ritalin LA and Concerta) and placebo in children with attention deficit hyperactivity disorder across the school day. Paediatr Drugs 5:545-555, 2003.

Losier BJ, McGrath PJ, Klein RM: Error patterns of the continuous performance test in non-medicated and medicated samples of children with and without ADHD: A meta-analytical review. J Child Psychol Psychiatry 37:971-987, 1996.

Markowitz JS, Straughn AB, Patrick KS, DeVane CL, Pestreich L, Lee J, Wang Y, Muniz R: Pharmacokinetics of methylphenidate after oral administration of two modified-release formulations in healthy adults. Clin Pharmacokinet 42:393-401, 2003.

Miller A: Assessment of attention deficit/hyperactivity disorder therapy: A Canadian perspective: A review of therapies for attention deficit/hyperactivity disorder Ottawa: Canadian Coordinating Office for Health Technology Assessment (CCOHTA), 1999.

National Institute of Mental Health: Early Clinical Drug Evaluation, Psychopharmacology Research Branch. In: ECDEU Assessment Manual for Psychopharmacology. Edited by Guy W. Rockville (Maryland), U.S. National Institute of Health, Psychopharmacology Research Branch, 1976, pp 217-222.

Patrick KS, González MA, Straughn AB, Markowitz JS: New methylphenidate formulations for the treatment of attention-deficit/hyperactivity disorder. Expert Opin Drug Deliv 2:121-143, 2005.

Pelham Jr. WE, Sturges J, Hoza J, Schmidt C, Bijlsma JJ, Milich R, Moorer S: Sustained release and standard methylphenidate effects on cognitive and social behaviour in children with attention deficit disorder. $\underline{\mathrm{Pe}}$ diatrics 80:491-501, 1987.

Pelham Jr. WE, Greenslade KE, Vodde-Hamilton M, Murphy DA, Greenstein JJ, Gnagy EM, Guthrie KJ, Hoover MD, Dahl RE: Relative efficacy of long-acting stimulants on children with attention deficit-hyperactivity disorder: A comparison of standard methylphenidate, sustained-release methylphenidate, sustained-release dextroamphetamine, and pemoline. Pediatrics 86: 226-237, 1990.

Pelham WE, Gnagy EM, Burrows-Maclean L, Williams A, Fabiano GA, Morrisey SM, Chronis AM, Forehand GL, Nguyen CA, Hoffman MT, Lock TM, Fielbelkorn K, Coles EK, Panahon CJ, Steiner RL, Meichenbaum DL, Onyango AN, Morse GD: Once-a-day Concerta methylphenidate versus three-times-daily methylphenidate in laboratory and natural settings. Pediatrics 107:e105, 2001.

Purdue Pharma Canada: Biphentin ${ }^{\circledR}$ (methylphenidate $\mathrm{HCl}$ ) Product Monograph. Pickering (Ontario), Purdue Pharma, 2006.

Quinn D, Bode T, Reiz JL, Donnelly GA, Darke AC: Single-dose pharmacokinetics of multilayer-release methylphenidate in children with attention-deficit/hyperactivity disorder. I Clin Pharmacol 47:760-766.
Reiz JL, Donnelly GAE, Michalko K: Comparative bioavailability of single-dose methylphenidate from a multilayer-release bead formulation and an osmmotic system: A two-way crossover study in healthy young adults. Clin Ther 30 2008, epub ahead of print.

Reynolds CR, Paget KD: National normative and reliability data for the Revised Children's Manifest Anxiety Scale. Sch Psychol Rev 12:324-336, 1983.

Riccio CA, Waldrop JJM, Reynolds CR, Lowe P: Effects of stimulants on the Continuous Performance Test (CPT): Implications for CPT use and interpretation. I Neuropsychiatry Clin Neurosci 13:326-335, 2001.

Swanson J, Volkow N: Pharmacokinetic and pharmacodynamic properties of stimulants: Implications for the design of new treatments for ADHD. Behav Brain Res 130:73-78, 2002.

Swanson J, Gupta S, Guinta D, Flynn D, Agler D, Lerner M, Williams L, Shoulson I, Wigal S: Acute tolerance to methylphenidate in the treatment of attention deficit hyperactivity disorder in children. Clin Pharmacol Ther 66:295-305, 1999.

Swanson JM, Wigal SB, Wigal T, Sonuga-Barke E, Greenhill LL, Biederman J, Kollins S, Nguyen AS, DeCory $\mathrm{HH}$, Hirshe Dirksen SJ, Hatch SJ; COMACS Study Group: A comparison of once-daily extended-release methylphenidate formulations in children with attention-deficit/hyperactivity disorder in the laboratory school (the Comacs Study). Pediatrics 113:e206-e216, 2004.

Tannock R, Schacher RJ et al.: Effects of methylphenidate on inhibitory control in hyperactive children. $\underline{\text { A Abnorm }}$ Child Psychol 17:473-491.

Wechsler D: Wechsler Intelligence Scale for children, $3^{\text {rd }}$ edition. San Antonio, (Texas). The Psychological Corporation, 1991.

Weiss M, Hechtman L, Turgay A, Jain U, Quinn D, Ahmed TS, Yates T, Reiz JL, Donnelly GAE, Harsanyi $\mathrm{Z}$, Darke AC: Once-daily multilayer-release methylphenidate in a double-blind, crossover comparison to immediate-release methylphenidate in children with attention-deficit/hyperactivity disorder. I Child Adolesc Psychopharmacol 17:675-688, 2007.

Wiig EH, Secord W, Semel E: Clinical Evaluation of Language Fundamentals, 3rd edition. The Psychological Corp, Harcourt Press, 1995.

Address reprint requests to: Joseph L. Reiz Purdue Pharma 575 Granite Court Pickering, Ontario, Canada, L1W 3W8

E-mail: joseph.reiz@purdue.ca 